Original Paper

\title{
GIS-based Multi-criteria Analysis for Urban Waste Management
}

\author{
Afsana AkTher ${ }^{\dagger}$, Tofael Ahamed, Tomohiro TakigaWA, and Ryozo Noguchi \\ (Received November 18, 2014)
}

\begin{abstract}
Urban solid waste management is a complex issue and an integrated concept in the developing world. In this study, we proposed a model for handling solid waste generation, collection, separation, and reduction. The model would help to manage municipal waste using a spatial geodatabase for waste disposal site selection and the location of suitable composting sites. The selection of composting sites for the conversion of organic waste to compost can reduce the volume of wastes and enhance urban agriculture. In this research, several factors in waste generation, including primary waste-generating site selection, road networks, municipal waste sites in sensitive locations, reasons for illegal waste dumping sites, and waste segregation were included. The interrelationships between these factors and manual waste handling, unsuitable techniques, limited manpower, logistics, and landfill scarcity conditions were investigated. Multi-criteria analysis was applied for the identification of suitable waste sites and selection of suitable composting sites for the promotion of urban agriculture. Thus, the research suggested a participatory approach for the reduction of domestic waste by source-separation and waste-conversion techniques. To map and visualize variation, Geographic Information System (GIS) was used to show the waste collection scenario, including sensitive locations, simultaneously dealt with several factors that were considered in the planning of waste management in a part of Dhaka City. A suitable composting site must follow environmental safety criteria in isolating waste and converting organic waste to compost with no risk to the environment. On the basis of exclusionary criteria, decision factors, and standardization and weighting of factors, a final suitability map was produced and potential locations for composting were identified. One of the notable outcomes of this research work was investigation of the most suitable site for composting, so as to introduce and promote urban agriculture.
\end{abstract}

\section{Key Words}

Solid Waste Management (SWM), GIS, Spatial Multi-Criteria Evaluation (SMCE), Urban Agriculture (UA), Composting

\section{Introduction}

Bangladesh is the ninth most populous country in the world. According to the United Nations Bank urban population growth in Bangladesh was at 3\% from 2010$2015^{1)}$, with this population growth, there is an increasing problem of waste management, particularly in the larger cities. Solid waste in cities is a natural outcome of human activities. In most cities and municipalities in developing countries, solid waste is a major concern of the government because of the health hazards associated with its improper disposal ${ }^{2)}$. The management of municipal solid waste is a substantial challenge for developing countries, particularly

Graduate School of Life and Environmental Sciences,

University of Tsukuba

1-1-1, Tennodai, Tsukuba-shi, Ibaraki 305-8572, Japan

$\dagger$ Corresponding author in larger urban areas ${ }^{3)}$. Rapid and unplanned urbanization leaves municipalities largely overwhelmed when it comes to the collection and disposal of increasing amounts of waste ${ }^{4)}$. Urban Solid Waste Management (USWM) is an urgent and challenging issue for Dhaka, one of the most populated cities in the world. The city corporation is the former selfgoverning corporation that is associated with the task of running the affairs of the city. Because of overpopulation and management aspects, the Dhaka City Corporation is divided into northern and southern regions. The north and south city corporations handle large amounts of solid wastes every day. Dhaka city generated 1,950 t/d of domestic waste from a population of 5.728 million, at an average rate of $0.34 \mathrm{~kg} /\left(\right.$ person d) ${ }^{5}$. The total solid waste amount from business sources is estimated at 1,050 t/d and the street 
waste at $200 \mathrm{t} / \mathrm{d}$. The annual rate of increase in solid waste has been estimated to an average of $1.2 \%$, which was found lower than the urbanization rate of approximately $4 \%$ and GDP growth of Bangladesh of about $6 \%{ }^{6}$.

At present an estimated 7,000 t of municipal solid waste (MSW) is generated daily in Dhaka City, of which only 1200-1500 t are disposed of in landfills and the rest is left unattended or dumped locally ${ }^{7}$. The city corporation states that the collection system cannot cope with the task of handling the large volume of waste produced by the growing number of city dwellers; only 40-50\% of the solid waste produced is being collected ${ }^{8)}$. The situation is unsatisfactory because of large increases in population and economic development and manual wastehandling techniques. Although Dhaka North and South City Corporations handle domestic and commercial waste, because of the limitations in resources and organizational capacity, it is difficult to ensure efficient waste management. The city needs major improvement in the separation of waste at source, storage, collection, transport, recycling, treatment, and disposal to reduce its adverse impact on the environment and public health. Accordingly, both city corporations are encouraging community-based organizations and local non-governmental organizations (NGOs) namely Primary Collection Service Providers (PCSPs), to provide house-to-house waste collection and transport to disposal sites. However, the efforts of PCSPs have yet not relieved city dwellers of the adverse impacts of inadequate solid waste management (SWM), including source separation and inefficient waste collection, by the city corporation. Even collection from dustbins for final disposal is to be made efficient because of the limited numbers of sanitary landfills and scarcity of land for waste disposal. Hence, this is high time to find out an alternative, like urban agriculture, which uses compost made from household organic waste. The shortage of manpower, logistics, and scarcity of landfill sites for disposing waste are issues of concern in the search for waste management solutions. The largest fraction by weight of mixed municipal waste consists of organic biodegradable waste, at 60-75\% ${ }^{8}$. Reducing the organic content, by composting or other organic waste treatment technology, would have a strong impact on reducing the volume of waste to be collected and disposed of. If organic waste remains unattended, it tends to decompose by natural processes, giving rise to odors, hosting and feeding a variety of insects and pests including carriers of disease, and creating severe health problems ${ }^{9}$. The bacterial conversion of organic materials in MSW in the presence of air under hot and moist conditions is called composting (aerobic composting), and the final product obtained after bacterial activity is called compost (humus), which has very high agricultural value and can be used as fertilizer; it is non-odorous and free of pathogens ${ }^{10)}{ }^{11}$. As a result of the composting process, waste is reduced by $50-85 \%$ in volume and can be used for urban agriculture by city dwellers ${ }^{12}$. Organic waste composting is effective and viable, but a sufficient market demand must be established and maintained. The conversion of waste biomass and organic substrates into energy encompasses a wide range of different types and sources of biomass conversion options, end-use applications, and infrastructure requirements ${ }^{13)}$. Organic residue is a good manure ${ }^{9}$. For energy production from waste biomass, several issues critical for all involved stakeholders, such as potential investors, involved regulators and decision makers, must be tackled ${ }^{14}$. Energy production from waste biomass and urban agriculture must be synchronized together with the potential identification of composting locations and geographical factors that would be safe for the environment. Urban agricultural policy can be an integral part of a set of policies for sustainable urban environmental management using composting and a proper geographical identification of location. To obtain a long term economic solution, sustainable techniques for composting and urban agriculture, including the bioenergy perspectives of GIS-based planning, can efficiently provide spatial and non-spatial information for proper USWM.

Currently, integrated GIS technology is recognized as one of the most promising approaches for the automation of the processes of waste planning and management ${ }^{15)}$. To improve the efficiency of waste collection and transport in the municipality of Nikaia, Athens, Greece, the reallocation of waste collection bins and optimization of vehicle routing was developed using ArcGIS Network Analyst ${ }^{16)}$. In another effort, a GIS-based method for the optimization of waste collection routes in the eastern Finland was used for the optimization of waste collection routes ${ }^{17}$. For sustainable waste management, urban waste reduction and reuse are important. GIS can assist in increasing the information and efficiency of the solid waste collection system in Dhaka city to reduce waste volume using a suitable dumping, recycling, and transportation system. In the context of Bangladesh, GIS-based approaches have been undertaken and have become a powerful tool for decision making in many respects. A GIS approach has been established for the energy assessment of different irrigation technologies. The spatial distribution of the uses, needs, and shortages of energy was analyzed for 64 districts of Bangladesh ${ }^{18}$. Cropping areas in the flood-prone areas of Bangladesh were assessed using GIS ${ }^{19}$. An assessment of energy status was 
performed to evaluate an alternative farming system for Bangladesh ${ }^{20}$. A GIS-based combined approach was applied to resource management for sustainable development ${ }^{21}$. In waste management, waste collection efficiency by the application of GIS to USWM in a part of Dhaka city was recently investigated ${ }^{22}$. However, the study conducted only one survey by questionnaire and collected the global positioning system (GPS) coordinates of existing waste bins, containers, and illegal disposal sites using a GPS device. The study was limited to the existing situation and did not consider reallocating or proposing the required numbers of waste collection bins.

Although there has been some research on USWM, the assessment of the suitability of composting site locations and reallocation of waste sites has yet to be performed for Dhaka city using GIS. Accordingly, the objectives of this study were as follows:

1. To develop a GIS-based scenario to characterize SWM practices including waste generation, the reallocation of waste bins and the type, size, relocation of waste sites and frequency of waste removal from the bins in one part of Dhaka city.

2. To identify suitable composting sites for initiating the segregation and collection of organic waste for composting and promotion of urban agriculture.

\section{Methodology}

\subsection{Study areas and data collection}

The study area was chosen under the jurisdiction of Rajhdhani Unnayan Kartipokkho (RAJUK) of Dhaka. Dhaka North City Corporation (DNCC), longitude between 90²0'E and $90^{\circ} 28^{\prime} \mathrm{E}$ and latitude between $23^{\circ} 44^{\prime} \mathrm{N}$ and $23^{\circ} 54^{\prime} \mathrm{N}$. DNCC consists of 36 wards with a total area of $82.638 \mathrm{~km}^{28)}$. The field survey was conducted during August-September, 2013 in ward 8 of zone 2 of DNCC. The total area of ward 8 was $3.048 \mathrm{~km}^{2}$, with 4,902 households. The base map of 2008 was obtained from the urban planning division of Dhaka City Corporation as shown in Fig. 1. The survey area consisted of 21 areas (locally called Mahalla) of ward 8. We evaluated problems that arose from shortcomings of the

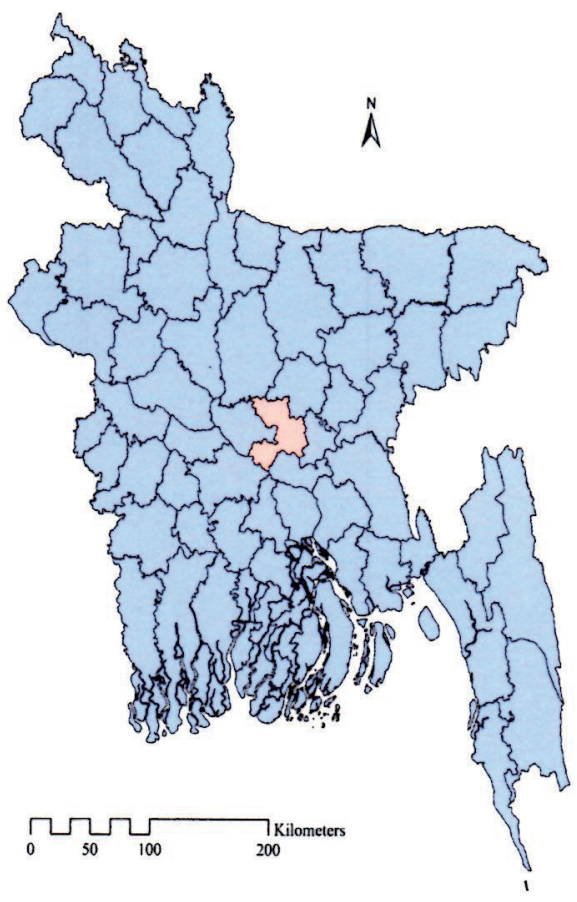

(a)

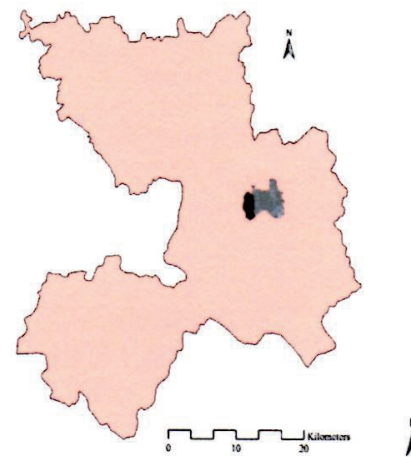

(b)

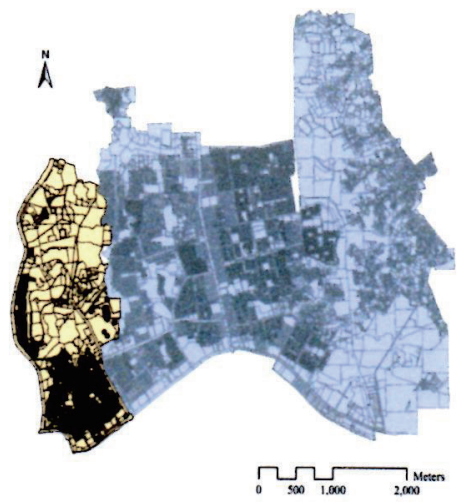

(c)

Fig. 1 Location of study area with waste site conditions in Dhaka: a) map of Bangladesh marked with Dhaka City, b) Dhaka City marked with zone 2, and c) Word 8 marked as study area in zone 2 
waste management system. A Detailed Area Plan (DAP) of RAJUK was used for the research.

\subsection{Waste generation sites}

This study was performed to develop waste management, including waste reduction and collection techniques, with geographical positions. The area where these waste sites located is indicated as DNCC large waste sites, DNCC small waste sites, and illegal waste sites as shown in Fig. 2. A total of 81 waste sites were identified, with $6 \%$ found to be DNCC large waste sites, $13 \%$ DNCC small waste sites, and $81 \%$ illegal waste sites created because of the inadequate provision of bins and access to waste collection bins as shown in Fig. 3. Technical criteria consisting of the size of the waste sites, truck parking for waste collection, access to waste disposal by PCSP, and distance from the main source of waste consumption were taken into consideration to identify very suitable, moderately suitable, or less suitable waste sites. Proximity analysis was performed with a $30 \mathrm{~m}$ buffer for all waste sites. Waste sites

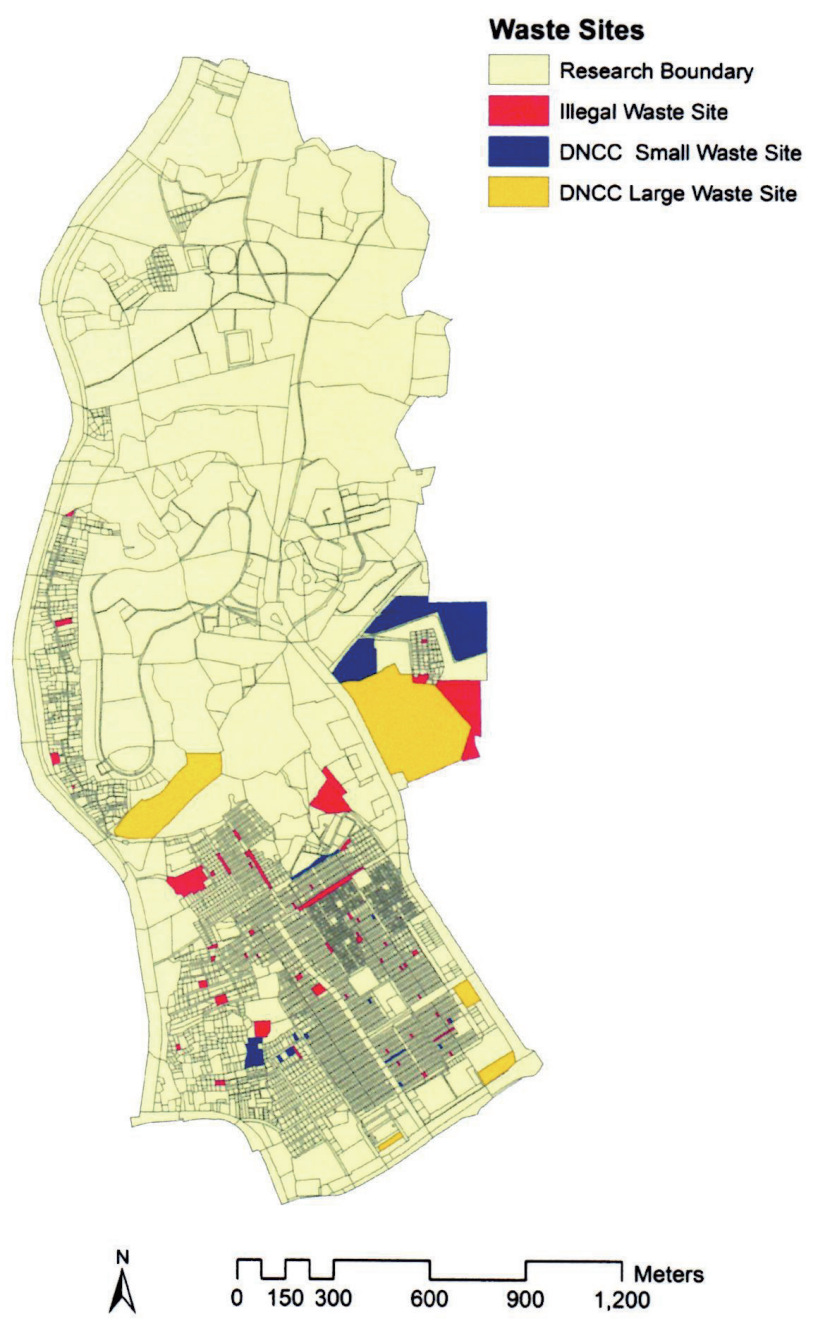

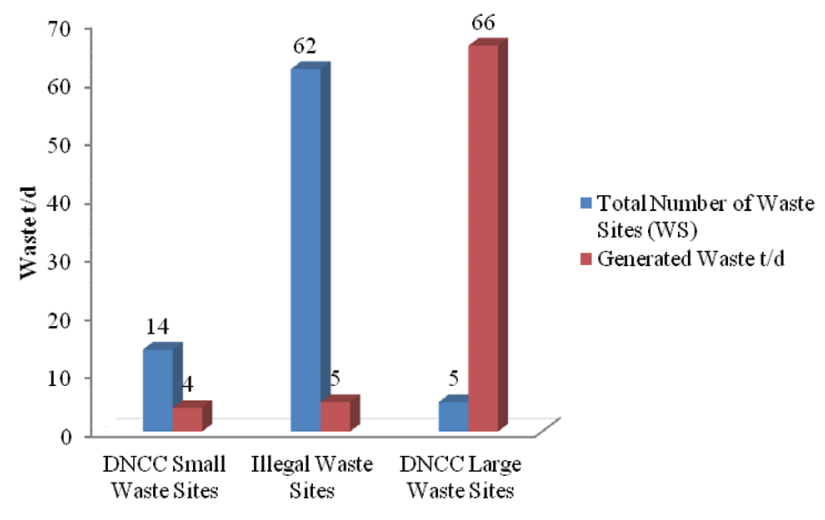

Fig. 3 Waste sites and generated wastes

Table 1 Waste site sensitivity (WSS) score

\begin{tabular}{l|l|c}
\hline $\begin{array}{c}\text { Waste sites Distance } \\
\text { (Meter) }\end{array}$ & \multicolumn{1}{|c}{ Waste sites Location } & Score \\
\hline $0-500$ & $\begin{array}{l}\text { Hospital, Mosque, Educational } \\
\text { Institution }\end{array}$ & 9 \\
& Road Intersection & 7 \\
& Residential Area & 5 \\
\hline $500-1,000$ & Residential Area & 3 \\
\hline $1,000-2,000$ & No sensitive site & 1 \\
\hline
\end{tabular}

located in close proximity to sensitive buildings, according to waste sensitivity scores of 7-9, were identified, and with high scores corresponding to high-sensitivity waste sites were suggested for relocation. The score is shown in Table 1.

\subsection{Data integration in GIS module}

This study analyzed the current waste management situation in the area. A conceptual framework and research diagram using GIS is proposed as shown in Fig. 4. ESRI ArcGIS $10^{\circledR}$ was used for mapping and data analysis. At the beginning, establishment of a spatial database of waste sites, availability of waste bins, waste segregation, type of waste site, waste collection trip, PCSP records, and land use and type based on environments. Secondly, GIS analysis was performed to visualize area wise collection status of waste, and identification of sensitive waste sites. Georeferencing was performed using WGS84 and BTM projections. A Garmin ${ }^{\circledR}$ handheld GPS was used to collect positional information to sub-meter accuracy. Thirdly, attributes were selected for composting sites applicable to vacant land for initiating urban agriculture and bioenergy plants. Fourthly, criteria and constraints were categorized to evaluate the attributes. Finally, GIS analysis was performed to find the best suitable composting site.

Fig. 2 Distribution of waste sites 


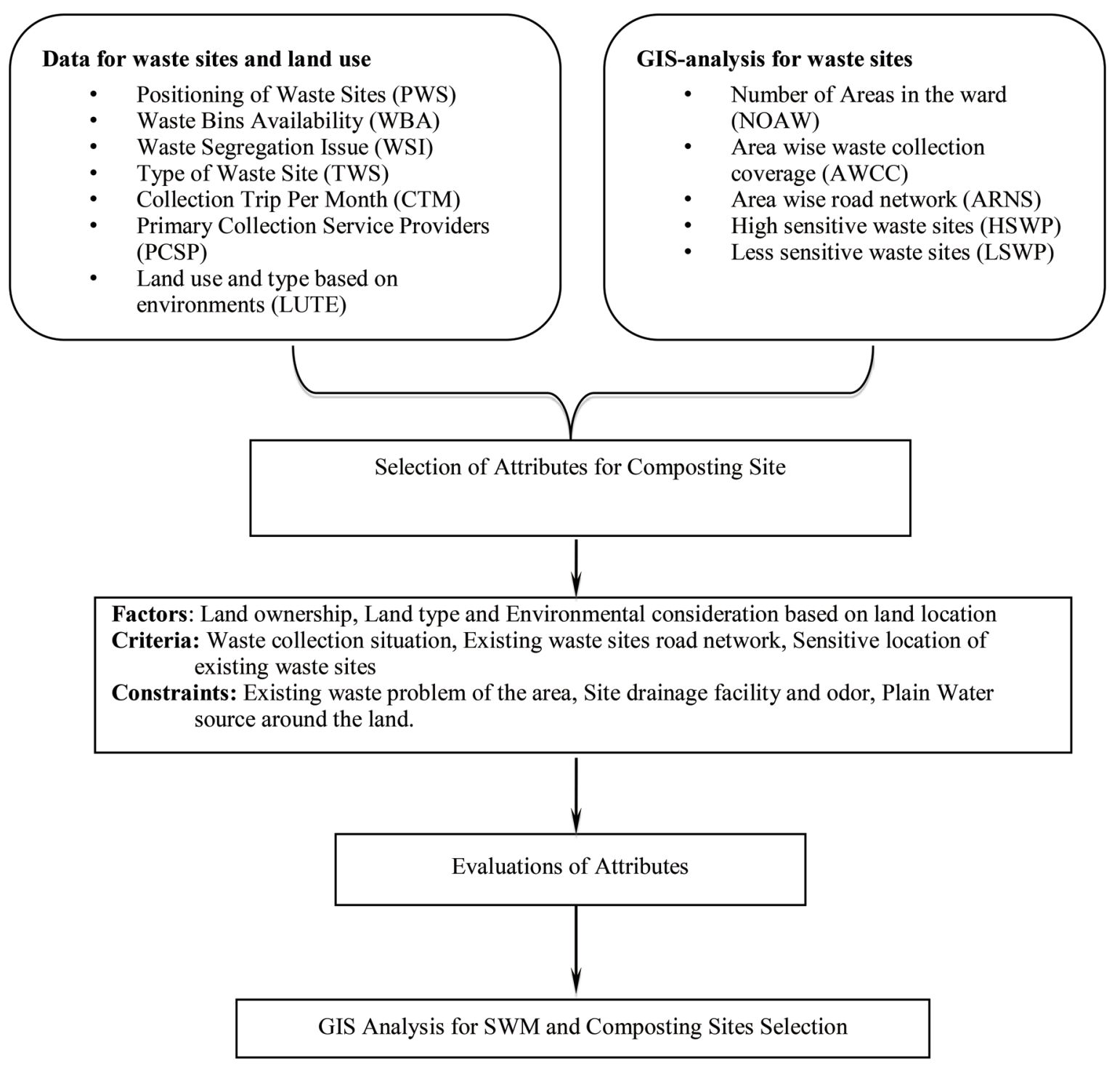

Fig. 4 Spatial Decision Support System (SDSS) for Solid Waste Management

\subsection{Spatial Multi-criteria Evaluation (SMCE)}

Multi-criteria analysis is a sequence of processes in which several decisions are made for problem recognition, and recommendations are generated ${ }^{23}$. In the evaluation process of SMCE data acquisition, storage, retrieval, and management functions were performed on the basis of the GIS database and converted to the real-world situation. The design phase involves developing and analyzing possible solutions to the problems identified in the searching phase as shown in Fig. 5. The site selection process was performed on the basis of the design phase and choice phase after obtaining the decisions of criteria and factors at the evaluation phase. SMCE was applied to identify potential areas on the basis of their socioeconomic characteristics to make final recommendations for the best composting sites in the study area for reducing the waste load.

The evaluation criteria characteristics reflect the impact of a site on several spatial (and sometimes nonspatial) aspects. These criteria can be assessed only for a potential site. The factors, criteria are listed in Fig. 5. In the choice phase of the site selection process, the suitability of each site identified as a potential site was assessed by multi criteria evaluation (MCE) analysis. In the study, vacant lands were identified for land suitability analysis. Among the sites, MCE analysis was performed considering factors of land ownership (public or private land), land type (wet or plain land), and environmental consideration based on land location, such as whether the vacant sites were within the locality or detached from the locality. These factors were scored by study criteria including waste collection conditions, road network, and sensitivity of waste site locations to these constraints or to obstacles such as poor PCSP service, unpleasant odors, and plain water source. 


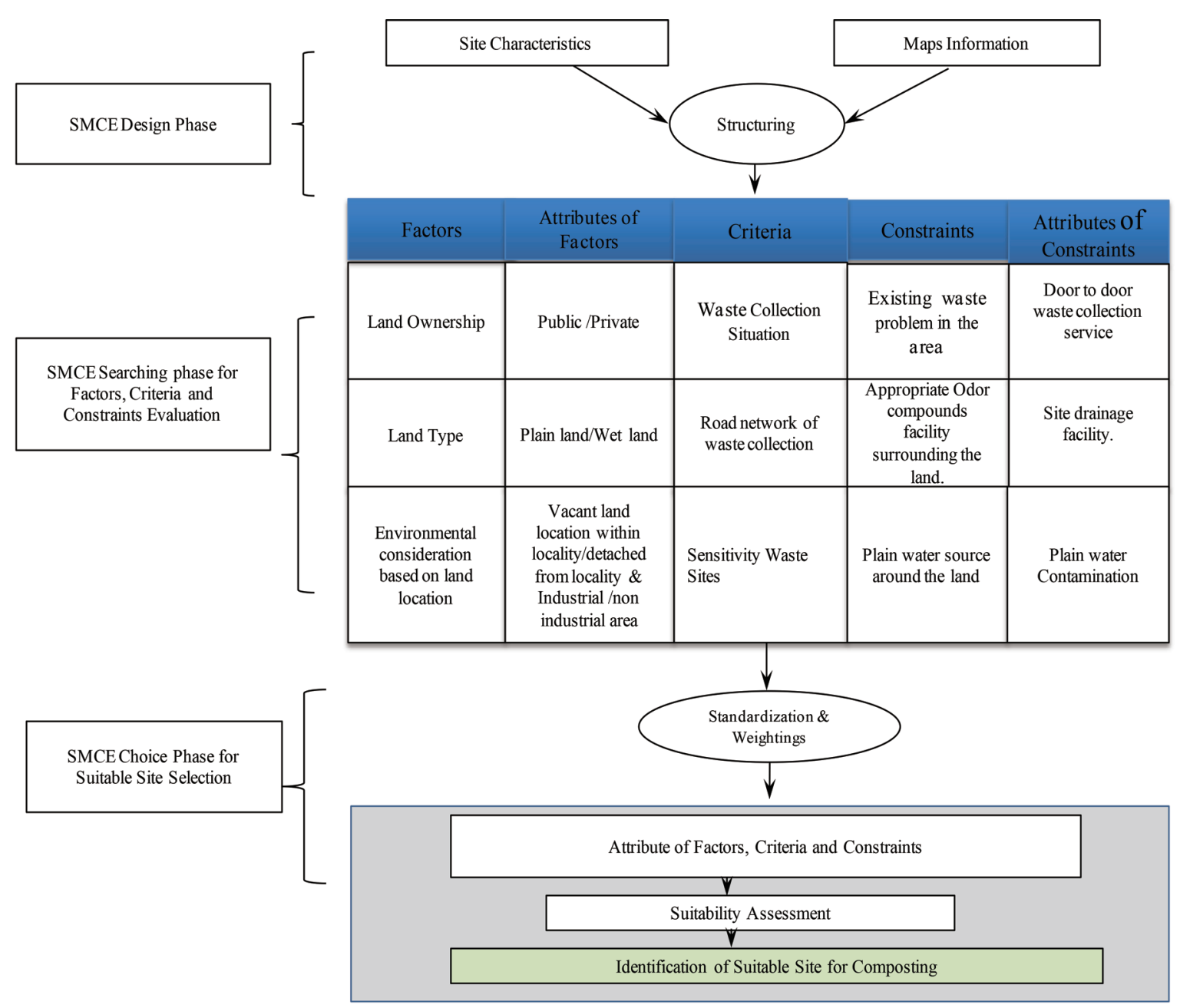

Fig. 5 Spatial Multi-Criteria Evaluation (SMCE) and selection of composting site

\subsection{Site selection and MCE}

By use of a weighted linear combination, factors were combined by application of a weight to each followed by summation of results to yield a suitability map. The weighted evaluation can be expressed as follows:

$$
S=\sum w_{i} x_{i}
$$

where, $S$ is suitability, $w$ are weights of the factors, and $x$ are criterion scores of the factors. The procedure was modified by multiplication by the suitability calculated from the factors and the constraints. The modified suitability can be expressed as follows:

$$
S=\left(\sum_{i=1}^{p} f_{i} w_{i}\right)\left(\prod_{j=1}^{q} r_{j}\right)
$$

where, $i$ is the factor, $p$ is the total number of factors, $f_{i}$ is the resultant summation between the weight of the factor and the type of the attribute for that factor and $w_{i}$ is the summation among the weight of the criteria. $j$ is the constraint and $q$ is the total number of constraints. $r_{j}$ is the product between the constraints and type of attribute for those constraints. While selecting the suitable composting sites, the vacant lands were evaluated with the presence of constraints and their attributes $(1,1)$ without (2 and 0 ).

\subsection{Reallocation of waste bins}

This analysis was implemented with spatial analysis functions on the basis of population density, waste collection equipment, waste container capacity, and daily stored waste amounts. The total number of required bins was calculated to cover the waste production of the sector. We considered the collection efficiency for all data sources to be approximately $50 \%$, apparently a theoretical assumption. The number of required bins $(\mathrm{N})$ was calculated from the following expression:

$$
N=\frac{W D}{V \times \rho \times \varepsilon}
$$

where, $W D(\mathrm{t})$ is the daily waste quantity including the waste deposited outside of the bin, $V\left(\mathrm{~m}^{3} / \mathrm{bin}\right)$ is the bin capacity, $\varepsilon$ is the coefficient of filling bin relates to waste density (0.80), $\rho$ is the waste density and considered from 0.35 to $0.80 \mathrm{t} / \mathrm{m}^{3}$. In this study $\rho$ was assumed as $0.56 \mathrm{t} / \mathrm{m}^{36)}{ }^{24)}$. 


\section{Results and Discussion}

\subsection{Reallocation of bins}

During the survey, we noted only 5 waste sites that were marked by the DNCC. All bins were found to be filled with waste exceeding the bin's capacity. It was observed that the study area needed more bins and more waste collecting sites. Table 2 summarizes this calculation. Ward 8 of DNCC was being managed with 5 large waste sites with 13 waste containers accepting $66 \mathrm{t}$-waste/d. The bin' s capacity was exceeded, and $13 \mathrm{t}$ of waste remained uncollected every day at the waste sites marked by the DNCC. The required numbers of bins were calculated. Additional 22 bins of different sizes were required to accommodate at the DNCC waste sites. Moreover for handling the over waste deposited in the DNCC small waste sites and Illegal sites, additional 4 bins were needed. For these bins allocation, 2 more waste sites can be identified from the less sensitive waste sites and could be managed by DNCC on a regular basis.

\subsection{Existing waste collection coverage}

A total of 81 waste generation sites were identified, together generating approximately 70-75 t-waste/d as shown in Fig. 6. The survey from this study found that $35 \%$ of areas waste remained fully uncollected. In contrast, doorto-door waste collection service by PCSP worked efficiently and $28 \%$ of the area was found clean with $100 \%$ turned out of waste. Other areas did not have door-to-door service, and we classified these areas as "around $50 \%$ waste uncollected", which occupied $37 \%$ of the survey area. The PCSP could not access these areas because of poor road networks and slums.

\subsection{Road Network of Existing Waste Sites}

Fig. 7 shows the area wise road network of waste sites. Among the 81 waste generation sites, $31 \%$ were located where the road network was very poor for waste collection, even vans could not enter for waste collection. But $30 \%$ waste generation sites were located on fair road networks and $39 \%$ were located on very good road networks. Most of the illegal waste sites were located in poverty-stricken, congested, and unsuitable places. DNCC vehicle access for waste collection was not possible at these sites.

\subsection{Highly sensitive and less-sensitive waste site locations}

Fig. 8 shows the identified high-sensitivity waste sites. Proximity analysis was performed with $30 \mathrm{~m}$ buffering, and 14 waste generation sites were found to be located in close proximity to sensitive buildings. These sites were considered high-sensitivity waste sites and suggested for relocation. The high-sensitivity waste sites were located near educational institutions, hospitals, or shopping malls, or in industrial, and high-traffic areas. At the same time, another analysis was performed to identify low-sensitivity waste sites for the relocation of high sensitive sites. To identify low-sensitivity waste sites, analysis was performed, and relocation sites were identified to which high-sensitivity waste sites could be relocated as shown in Fig. 9. A $30 \mathrm{~m}$ buffer was established for all waste sites for choosing the best suitable waste collecting sites. A total of 19 sites were identified as low-sensitivity waste sites. Environmentally lower-sensitivity and convenience proximity distance can be given priority for continuing the waste collection of door-to-

Table 2 Bin status with over carrying waste, without over carrying waste and reallocation of bins

\begin{tabular}{c|c|c|c|c|c|c|c}
\hline Waste Sites & $\begin{array}{c}\text { Bins } \\
(\text { Existing })\end{array}$ & $\begin{array}{c}\text { Capacity of } \\
\text { bin } \\
\left(\mathrm{m}^{3} / \mathrm{bin}\right)\end{array}$ & $\begin{array}{c}\text { Waste stored } \\
\text { in bin } \\
(\mathrm{t} / \mathrm{d})\end{array}$ & $\begin{array}{c}\text { Over carrying } \\
\text { waste } \\
(\mathrm{t} / \mathrm{d})\end{array}$ & $\begin{array}{c}\text { Total waste bin and } \\
\text { out of the bin } \\
(\mathrm{t} / \mathrm{d})\end{array}$ & $\begin{array}{c}\text { Total numbers } \\
\text { of bin required }\end{array}$ & $\begin{array}{c}\text { Additional bins } \\
\text { need to allocate }\end{array}$ \\
\hline (A) & (B) & (C) & (D) & (E) & $F_{\text {Total }}=\left(D_{\text {Subtotal }}+E_{\text {Subtotal }}\right)$ & $(\mathrm{G})$ & $\begin{array}{c}H_{\text {Total }}= \\
\left(G_{\text {Subtotal }}-B_{\text {Subtotal }}\right)\end{array}$ \\
\hline
\end{tabular}

Over carrying waste

\begin{tabular}{|c|c|c|c|c|c|c|c|}
\hline Eid Gah Moidan & 3 & 5 & 15 & 3 & 18 & 8 & 5 \\
\hline Rainkhola Bazar & 4 & 3 & 12 & 3 & 15 & 11 & 7 \\
\hline Beribadh & 1 & 3 & 3 & 2 & 5 & 4 & 3 \\
\hline Muktijoddha market & 4 & 5 & 20 & 5 & 25 & 11 & 7 \\
\hline \multicolumn{8}{|l|}{ Not over carrying waste } \\
\hline Sony Cinema Hall & 1 & 3 & 3 & 0 & 3 & 1 & 0 \\
\hline Sub Total & 13 & & & 13 & 66 & 35 & 22 \\
\hline $\begin{array}{l}\text { Illegal waste and DNCC } \\
\text { small Waste sites waste }\end{array}$ & 0 & 5 & 0 & 9 & 9 & 4 & 4 \\
\hline Subtotal & 13 & & 53 & 22 & & 39 & \\
\hline Total & 13 & & & & 75 & & 26 \\
\hline
\end{tabular}




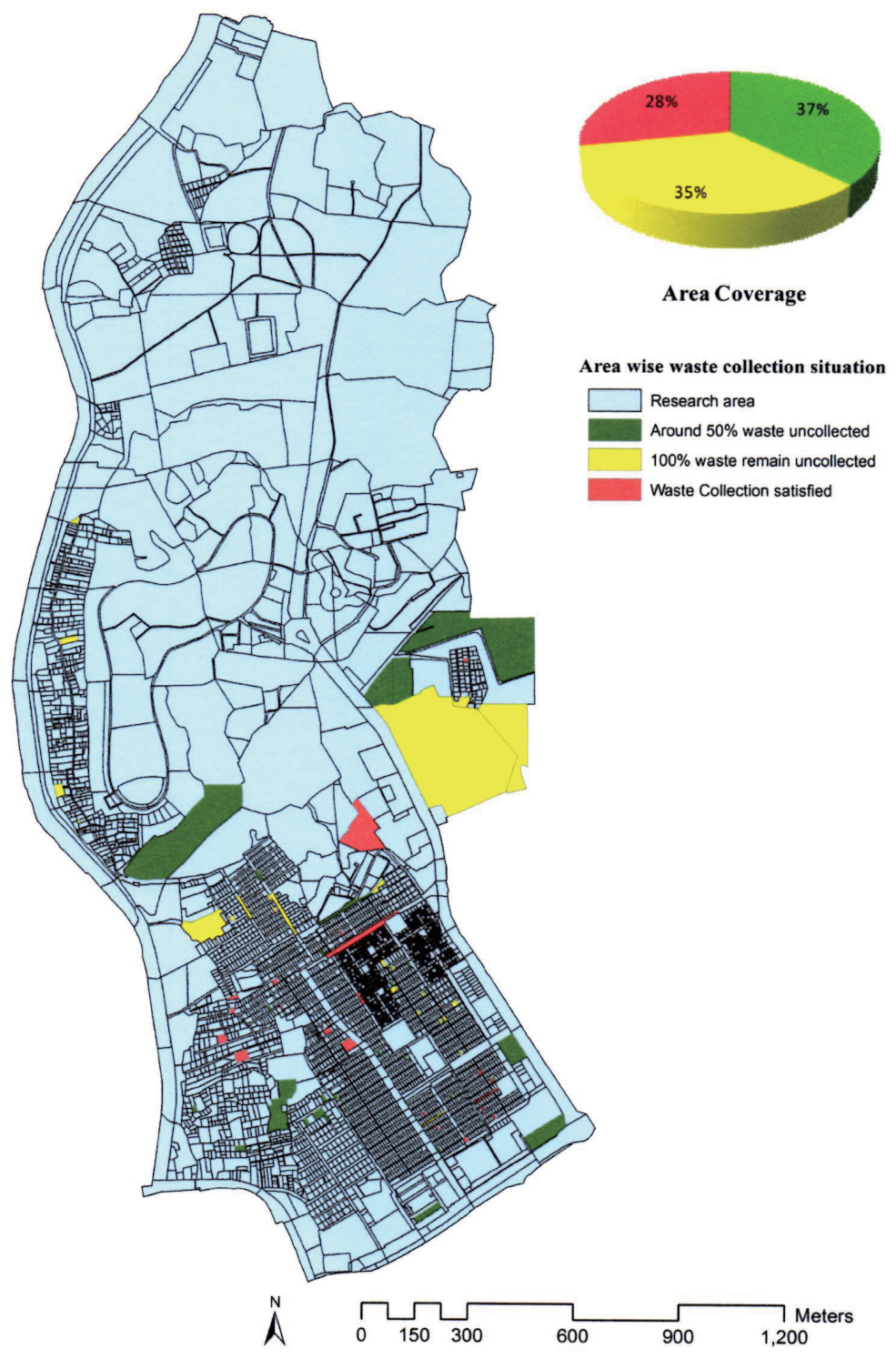

Fig. 6 Area wise waste collection situation

door service by PCSP and DNCC.

\subsection{Initiative of urban agriculture}

The result of survey of household owners is shown in Fig. 10. The owners were interested in gardening on their rooftops, as there were no vacant spaces around their homes. The survey also showed that the $37 \%$ household owners were well informed about urban agriculture. However, $63 \%$ of the respondents were not well informed about sustainable urban agriculture at the household level. The questionnaire was extended further and it was observed that $89 \%$ household owners were interested in composting with the support of the local government or nonprofit organization. The owners were interested in segregating organic waste at home, if the local government took steps toward composting. We noted that $90 \%$ of household owners agreed that conversion of organic waste to compost would be one of the best ways for reducing waste volume and ensuring the cleanliness of the area.

Some sites were selected as suitable composting sites by the SMCE analysis as shown in Fig. 11. In total, 455 vacant land sites were used for land suitability analysis, among them suitable composting sites were identified. Two areas, Al-Kamal Housing and Uttar Bishil, were identified as the two suitable composting sites among the 455 vacant lands. Furthermore, a proximity analysis was done to get the information of nearest features for these two areas. In case of Uttar Bishil, one of the main roads passed through this area, which made it as a potential business area. The proximity analysis also extended for Al Kamal Housing site, which was found as protected area and had less influence of nearest features. Therefore, Al-Kamal Housing site was 


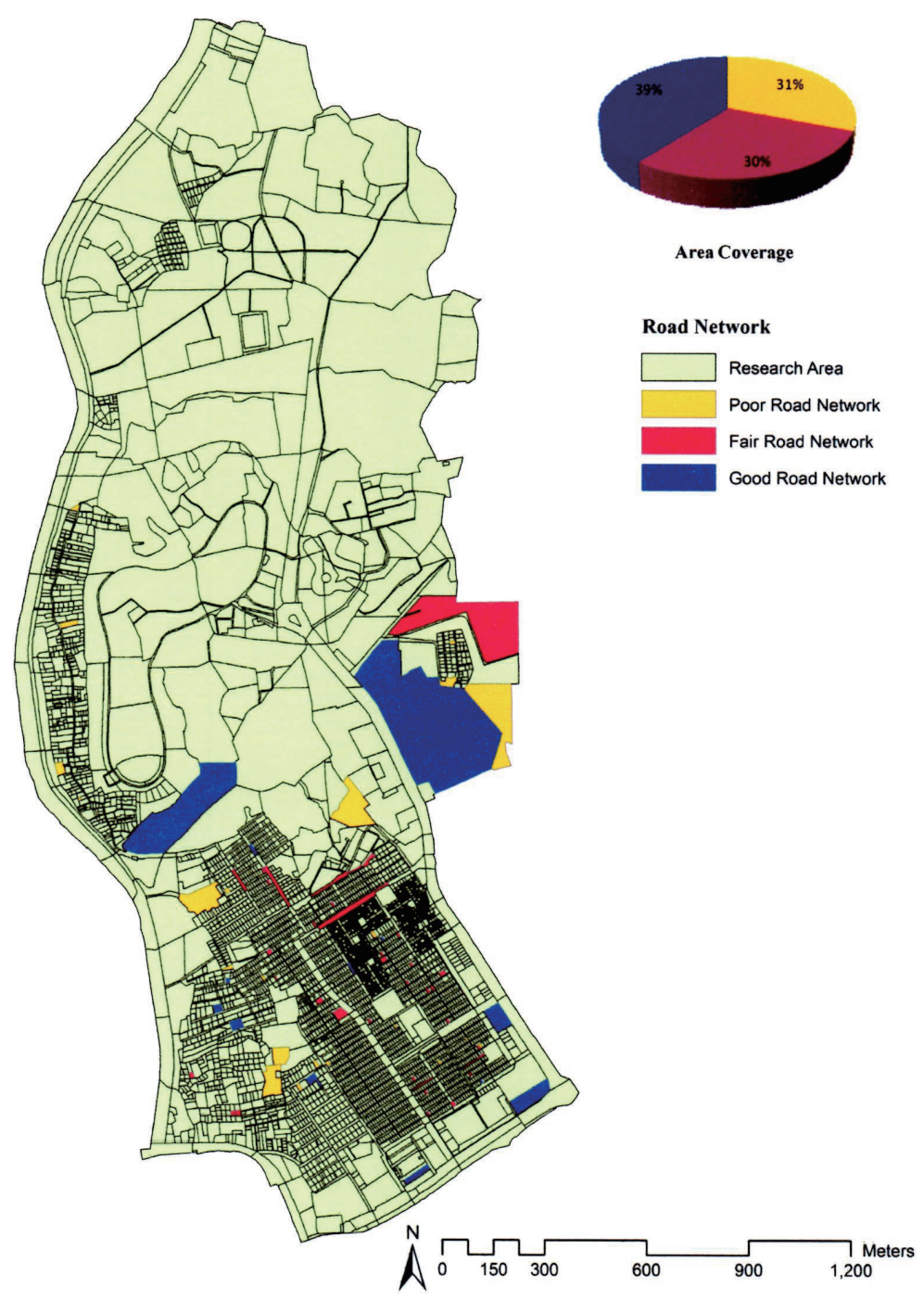

Fig. 7 Area wise road network of waste sites

ranked highest and recommended as the best composting site as it was matched within the required land space and less influence of nearest features.

\section{Conclusions}

This study was conducted to develop a GIS-based management plan for the administrative area of ward 8 , selected from Zone 2 under the DNCC. Ward 8 had a shortage of waste-collecting sites and bins. The bins were overloaded beyond their capacity at the designated collecting sites. Because of the insufficiency of waste collection sites, numbers of illegal sites were increased. GISbased analysis identified the unsuitable waste sites that included sensitivity of that location. The relocation of these unsuitable waste sites was proposed with the required number of bins according to generated wastes. Moreover, at waste collection sites, wastes included both decomposable and non-decomposable wastes. Segregation of waste at the household level was very desirable. It was observed that organic waste in the study area accounted more than $60 \%$ of total waste. According to the survey, $89 \%$ of household owners were interested in composting to use in their rooftops or in their yards for the promotion of urban agriculture. Increasing awareness of the benefits of waste segregation and conversion to compost was needed for improving livelihoods. The best-identified composting location was found through the SMCE and proximity analysis. The best-composting site, Al-Kamal Housing could enhance urban agriculture and create an extra incentive to the community to segregate organic wastes. Therefore, the GIS-based SWM model could be incorporated to reduce illegal disposal of waste, for the availability of waste collecting bins, and suitable composting sites for sustainable urban management of Dhaka.

\section{References}

1) United Nations, World Statistics Pocket Book, United Nations Statistics Division, Department of Economic 


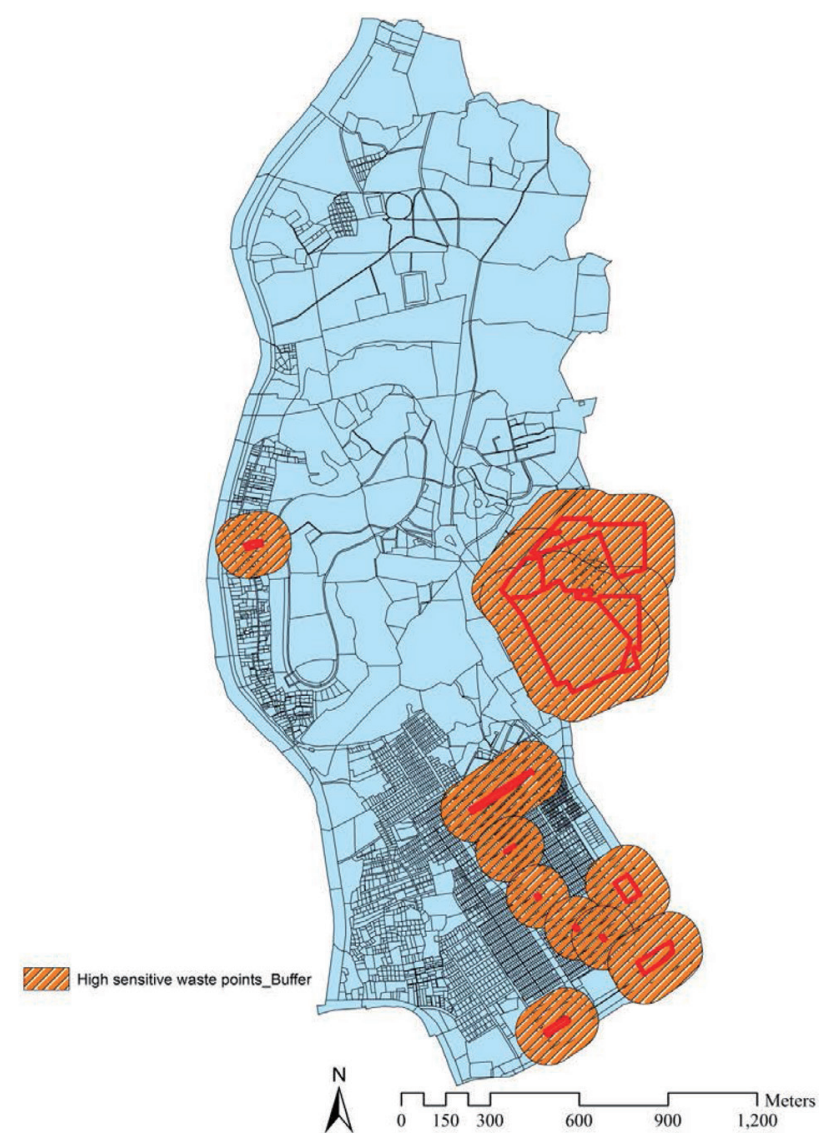

Fig. 8 Identified high-sensitivity waste sites

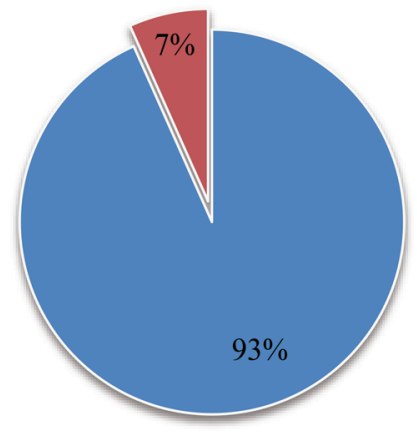

$\square$ No vaccant land for UA $\square$ Vaccant land for UA

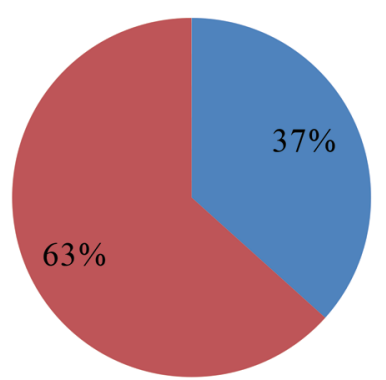

- Idea of UA $\quad$ No idea about UA

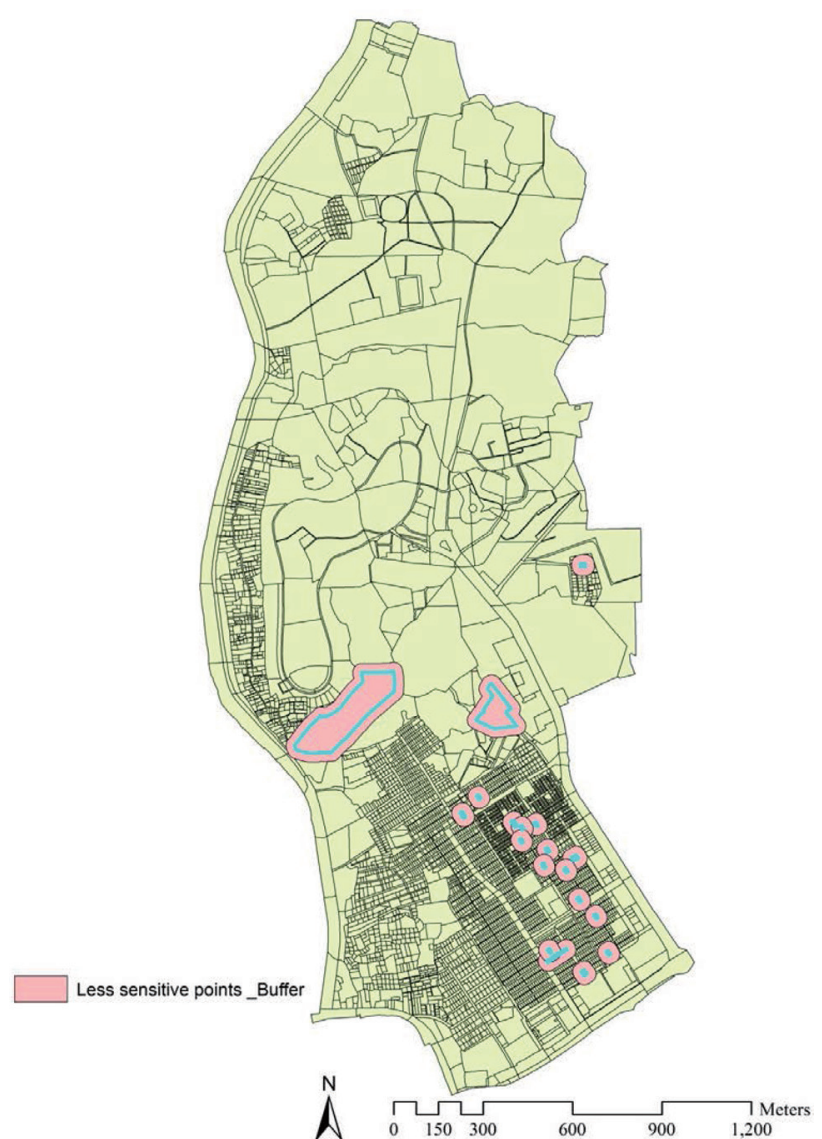

Fig. 9 Identified lower-sensitivity waste sites

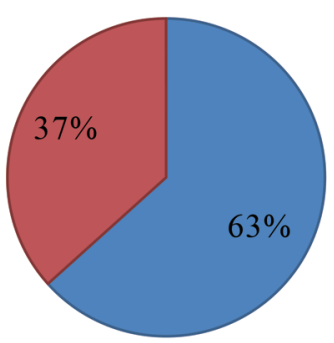

$\square$ Plan of rooftop garden $\square$ No plan for rooftop garden

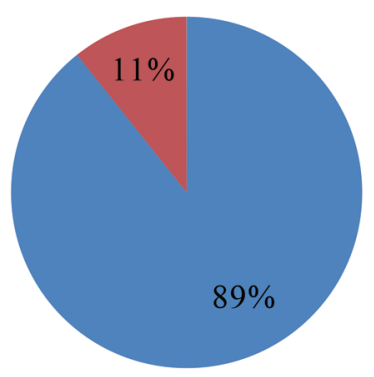

- Interest of UA using compost $\quad$ Not interested

Fig. 10 Household survey for the initiative of urban agriculture 


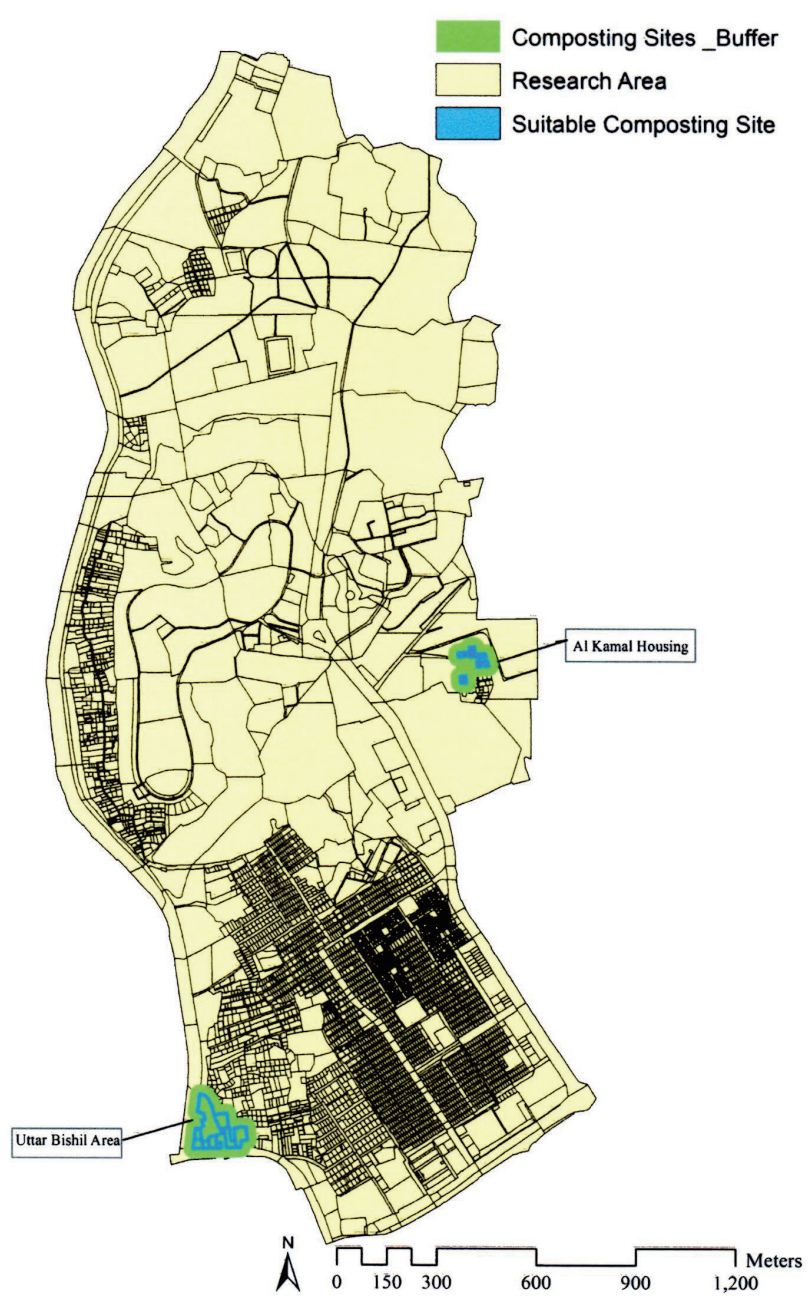

Fig. 11 Identified composting sites for initiating urban agriculture through the conversion of organic waste

and Social Affairs Division2014, Series 5(10), p. 17-18 (2014)

2) Paul, S., International Journal of Geomatics \& Geosciences, 3(1), (2012)

3) Scheinberg. A.; Wilson, D. C.; Rodic, L., Solid Waste Management in the world's cities, Un Habitat Third Global Report on the State of Water and Sanitation in the World's Cities Earth Scan (2010)

4) Medina, M., Waste Management and Research, 23, 390397 (2005)

5) JICA Clean Dhaka Master Plan, Final Report, (2005)

6) Yousuf, T. B.; Rahman, M., Journal of Environmental Monitoring and Assessment, 135(1-3), 3-11 (2007)
7) Hasan, R.; Tetsuo, K.; Ataharul, S., Journal of Civil Engineering (IEB), 37(2), 133-149 (2009)

8) Dhaka North City Corporation, http://www.dncc.gov. bd/dncc-setup/geographical-location-area-of-dncc.html, (Last accessed: June 21, 2015)

9) Sharholy, M.; Ahamad, K.; Mahmud, G.; Trivedi, R. C., Waste Management, 28, 459-467 (2008)

10) Ahsan, N., Indian Journal of Environment Protection, 19(2), 90-95 (1999)

11) Khan, R. R., Indian Journal of Environmental Protection, 22(4), 444-448 (1994)

12) Matteret, A.; Dietschi, M.; Zurbrugg, C., Habitat International, 150-156 (2013)

13) Karagiannidis, A.; Wittmaier, M.; Langer, S. Bilitewski, B.; Malamakis, A, Renewable and sustainable energy, 13, 2156-2162 (2009)

14) Iakovou, E.; Karagiannidis, A.; Vlachos, D.; Toka, A.; Malamakis, A., Waste management, 30, 1860-1870 (2010)

15) Karadimas, N. V.; Loumos, V. G., Waste Management \& Research, 26, 337-346 (2008)

16) Chalkias, C.; Lasaridi, K., WSEAS Transaction on Environment and Development, 5(10), 640-650(2009)

17) Nuortio, T.; Kytojokib, J.; Niska, H.; Brysy, O., Expert Systems with Application, 30, 223-232 (2006)

18) Ahamed, T.; Takigawa, T.; Koika, M.; Hossain, M. M.; Huq M. M.; Faruq, M. O., Energy, 31, 2681-2704 (2006)

19) Faruk, M. O.; Ahamed, T., Journal of Institution of Engineers, 29, 67-71(2002)

20) Ahamed, T.; Takigawa, T.; Koika, M.; Hossain, M. M., Huq, M. M., Faruk, M. O., Japanese Journal of Farm work Research, 38(4), 221-236 (2003)

21) Ahamed, T.; Takigawa, T.; Koika, M.; Khan, M. I. N.; Tasnim, F.; Zaman, J. M. Q., Environment Development Sustainability, 11, 933-954 (2009)

22) Rahman, S. H., Journal of Sustainable Development and Environmental Protection, 1(2), Jul-Sep (2011)

23) Shari, M. A.; Retsios, V., Journal of Telecommunication and Information Technology, 3, 1-10 (2004)

24) BUET, Characterization of municipal solid waste and preliminary environmental impact assessment of collection and disposal works in Dhaka city, Department of Civil Engineering, Bangladesh University of Engineering and Technology, Project Report, BRTC and DCC (2000) 